\title{
SISTEM INFORMASI OBJEK WISATA JELITIK, KABUPATEN BANGKA BERBASIS WEBSERVER
}

\author{
Fardhan Arkan \\ Jurusan Teknik Elektro FT UBB \\ Email:: fardhan-arkan@ubb.ac.id
}

\begin{abstract}
Bangka has a beautiful tourist destination and attract tourists to visit, especially coastal tourism. One of them is a tourist destination in the village of Jelitik with beautiful and interesting beach tourism potential and is in one lane so that tourists have many options when visiting. Jelitik has beach tourism from Rambak Beach, Pantai Tikus, Tanjung Pesona, Pesona Bay and Tikus Mas Beach which is well known and widely visited by local people around Bangka. Currently, Jelitik does not have information system to provide complete information about the existing tourist attraction so as to facilitate the tourists when visiting. With the information system of this tourist attraction will facilitate the outsiders who want to know about tourist destinations in Jelitik and can be accessed using the Internet and introduce the tourist attraction widely to increase tourist arrivals. The tourist information system will make tourism in Jelitik will be widely known and make tourists who visit will get complete information. The development of information system of this tourist object will be based on webserver for management. The system will also build maps and profiles of this tourist destination is expected to introduce tours in Jelitik widely to the public using the Internet
\end{abstract}

Keywords: Information System, Tourism, Webserver

\section{INTISARI}

Bangka mempunyai objek wisata yang indah dan menarik wisatawan untuk berkunjung, terutama wisata pantai. Salah satunya adalah objek wisata di kelurahan Jelitik dengan potensi wisata pantai yang indah dan menarik dan berada dalam satu jalur sehingga wisatawan memiliki banyak pilihan wisata ketika berkunjung. Kelurahan Jelitik memiliki wisata pantai dari Pantai Rambak, Pantai Tikus, Tanjung Pesona, Pesona Bay serta Pantai Tikus Mas yang sudah dikenal dan banyak dikunjungi oleh masyarakat lokal di sekitar Bangka. Saat ini, Jelitik belum memiliki sistem informasi untuk memberikan informasi lengkap tentang objek wisata yang ada tersebut sehingga memudahkan wisatawan ketika berkunjung. Dengan sistem informasi objek wisata ini akan memudahkan pihak luar yang ingin mengetahui tentang destinasi wisata di Jelitik dan bisa diakses menggunakan Internet serta memperkenalkan objek wisata tersebut secara luas untuk meningkatkan kunjungan wisatawan. Sistem informasi objek wisata tersebut akan membuat wisata di Jelitik akan dikenal secara luas dan membuat wisatawan yang berkunjung akan mendapatkan informasi yang lengkap. Pembangunan sistem informasi objek wisata ini akan berbasis webserver untuk pengelolaan. Sistem ini juga akan membangun peta dan profil destinasi wisata ini diharapkan dapat memperkenalkan wisata di Jelitik secara luas kepada masyarakat memanfaatkan Internet.

Kata Kunci: Sistem Informasi, Wisata, Webserver

\section{PENDAHULUAN}

Pariwisata telah menjadi target pemrintah untuk terus dikembangkan dengan cara meningkatkan pendapatan negara sehingga Pemerintah berusaha untuk meningkatkan kunjungan wisatawan ke Indonesia. Berwisata adalah salah satu aktivitas yang sangat di gemari oleh masyarakat baik dalam negeri maupun luar negeri dengan tujuan berekreasi bersama keluarga dan teman-teman ditengah sibuknya kegiatan. Objek wisata dapat juga merupakan aset penting bagi suatu daerah, karena dengan adanya aset pariwisata tersebut, maka banyak orang mengenal dan mengetahui daerah tersebut. Di Kabupaten Bangka telah memiliki banyak aset-aset pariwisata yang menjadi simbol bagi Propinsi Kepulauan Bangka Belitung antara lain Pantai Parai Tenggiri, Pantai Tanjung Pesona, Puri Tri Agung dan lainnya. 
Dari aset pariwisata yang dimiliki oleh Kabupaten Bangka ada beberapa tempat yang masyarakat belum mengetahuinya secara luas dan ada juga masyarakat yang mengetahui aset pariwisata tersebut tetapi tidak mengetahui lokasi tempat pariwisata karena keterbatasan informasi yang tersedia terutama di Kabupaten Bangka. Hal ini menyebabkan masyarakat di Kabupaten Bangka dan luar Pulau Bangka kurang mengetahui informasi dari aset-aset pariwisata yang dimiliki oleh daerahnya sendiri.

Kabupaten Bangka yang memiliki banyak tempat wisata adalah Kelurah Jelitik yang memiliki daerah wisata Pantai yang sudah terkenal di Kabupaten Bangka tetapi belum diketahui secara luas di Kabupaten Bangka. Pantai tersebut antara lain Pantai Rambak, Tikus, Tanjung Pesona dan Tikus Mas. Karena itu diperlukan sebuah sistem informasi yang lengkap untuk memberikan informasi tentang wisata yang ada di Jelitik.

Oleh karena belum tersedianya website pariwisata sehingga tempat wisata yang ada di Kabupaten Bangka hanya dipromosikan dari mulut ke mulut, serta dari website yang menampilkan gambar destinasi yang ada di Bangka dengan tampilan yang menarik. Hal ini tentu belum efektif sehingga jumlah wisatawan tidak meningkat serta hanya ada wisatawan lokal dari sekitar Bangka saja. Seharusnya dengan destinasi wisata yang banyak dan indah dapat membuat wisatawan lokal dan luar datang berkunjung ke Jelitik, Kabupaten Bangka. Dengan mengelola informasi pariwisata yang baik dan dapat diakses melalui Internet maka efek pariwisata dapat lebih berdampak bagi masyarakat Kabupaten Bangka serta meningkatkan ekonomi masyarakat. Berdasarkan observasi lapangan, kami menemukan bahwa destinasi pariwisata di Kabupaten Bangka kurang dikenal secara luas dikarenakan tidak adanya pusat informasi yang lengkap dan baik sehingga orang dapat mengetahui dan mengenal serta tertarik datang ke Kabupaten Bangka Barat untuk berwisata.

Melihat begitu pentingnya informasi dari sebuah aset pariwisata dan lokasi pariwisata di Jelitik, Kabupaten Bangka, maka untuk menyediakan informasi tersebut diperlukan website, karena website merupakan penyedia informasi yang dapat diakses semua kalangan menggunakan Internet. Penelitian ini akan membuat pusat informasi wisata berbasis website dengan menggunakan peta dan membangun profil wisata yang ada di Jelitik agar mudah dikenal oleh orang luas. Website ini akan dibangun dengan data yang lengkap dan dengan tampilan yang menarik.

\section{METODE PENELITIAN}

\section{A. Data, Informasi dan Sistem Informasi}

Data merupakan deskripsi tentang benda, kejadian, aktivitas, dan transaksi yang tidak mempunyai makna atau tidak berpengaruh secara langsung kepada pemakai. Data juga dapat diartikan suatu bahan mentah yang kelak dapat diolah lebih lanjut untuk menjadi sesuatu yang lebih bermakna. Dan data inilah yang nantinya akan disimpan dalam database. Sedangkan Informasi adalah data yang telah diolah menjadi sebuah bentuk yang berarti bagi penerimanya dan bermanfaat dalam pengambilan keputusan saat ini atau saat mendatang.

Sistem informasi adalah kumpulan antara sub sub sistem yang saling berhubungan yang membentuk suatu komponen yang didalamnya mencakup input-proses-output yang berhubungan dengan pengolahan data menjadi informasi sehingga lebih berguna bagi pengguna [1]. 


\section{B. Pariwisata}

Menurut Kamus Besar Bahasa Indonesia (KBBI), istilah "pariwisata" merupakan nomina (kata benda) yang berarti: Yang berhubungan dengan perjalanan untuk rekreasi, pelancongan, turisme.

\section{Definisi Pariwisata}

Menurut World Tourism Organization, definisi pariwisata adalah pergi "melampaui persepsi umum pariwisata sebagai hal yang terbatas pada kegiatan liburan saja" dan sebagai orangorang "yang bepergian ke dan tinggal di tempat-tempat di luar lingkungan mereka selama tidak lebih dari satu tahun berturutturut untuk bersantai, bisnis, dan tujuan lain.

\section{Pengertian Pariwisata Menurut Para Ahli}

Menurut Robert McIntosh, pariwisata adalah gabungan dari interaksi antara pemerintah selaku tuan rumah pariwisata, bisnis, dan wisatawan.

Menurut Herman V. Schulard, pariwisata adalah sejumlah kegiatan terutama yang ada kaitannya dengan perekonomian secara langsung berhubungan dengan masuknya orangorang asing melalui jalur lalu lintas di suatu negara, kota, dan daerah tertentu.

\section{E. PHP (Hypertext Preprocessor)}

"PHP atau singkatan dari Personal Home Page merupakan bahasa skrip yang tertanam dalam HTML untuk dieksekusi bersifat server side". PHP termasuk dalam open source product, sehingga source code PHP dapat diubah dan didistribusikan secara bebas. Versi terbaru PHP dapat diunduh secara gratis melalui situs resmi PHP : http://www.php.net
PHP juga dapat berjalan pada berbagai web server seperti IIS (Internet Information Server), PWS (Personal Web Server), Apache, Xitami. PHP juga mampu berjalan di banyak sistem operasi yang beredar saat ini, diantaranya : Sistem Operasi Microsoft Windows (semua versi), Linux, Mac Os, Solaris. PHP dapat dibangun sebagai modul web server Apache dan sebagai binary yang dapat berjalan sebagai CGI (Common Gateway Interface). PHP dapat mengirim HTTP header, dapat mengatur cookies, mengatur dan mengelola authentication dan redirect user.

\section{F. MySQL}

MySQL adalah Relation Database Management System (RDBMS) yang didistribusikan secara gratis di bawah lisensi GPL (General Public License). Beberapa database relasional yang menggunakan SQL adalah: MySQL, Oracle, Sybase, Microsoft SQL Server, Access, Ingres, etc. Meskipun sebagian besar sistem database menggunakan SQL, namun sebagian besar dari mereka juga memiliki ekstensi khusus yang hanya bisa digunakan di sistem masing-masing. Namun demikian, perintah standar SQL seperti "Select", "Insert", "Update", "Delete", "Create", dan "Drop" dapat digunakan untuk melakukan hampir semua hal yang perlu dilakukan terhadap sebuah database.

\section{G. Gambaran Umum Sistem}

Dengan sistem informasi pariwisata ini, pengelolaan pariwisata lebih ditekankan pada pemanfaatan Internet dan smartphone berbasis android sehingga semua orang dapat mengetahui wisata yang ada di Jelitik, Kabupaten Bangka. Hal ini karena potensi pariwisata di Kabupaten Bangka Barat cukup tinggi dikarenakan 
banyak destinasi wisata yang banyak dikenal dan dikunjungi wisatawan.

Untuk membangun website pariwisata dapat menggunakan PHP dan MySQL serta merancang tampilan yang menarik sehingga orang tertarik dengan informasi dalam website pariwisata yang dibangun. Selain itu, data dalam website pariwisata ini haruslah lengkap sehingga orang merasa senang dan tertarik berkunjung ke wisata yang ada di Jelitik, Kabupaten Bangka

\section{H. Spesifikasi sistem}

Spesifikasi dari sistem yang dibuat pada penelitian ini sebagai berikut :

1. Seluruh data sistem pariwisata akan tersimpan secara terpusat dan terstruktur pada sebuah database menggunakan MySQL

2. Untuk mengakses database tersebut dikembangkan dalam bentuk web database yang dihubungkan internet serta dapat diakses melalui website

3. Untuk tampilan website dirancang agar memiliki tampilan yang menarik dengan data pariwisata Jelitik yang lengkap untuk disampaikan kepada pengunjung

\section{Perancangan Perangkat Lunak}

Blok fungsional dari sistem yang dibuat pada penelitian ini secara keseluruhan dapat dilihat pada gambar 1 dibawah ini.

Pada Gambar 1. dapat dilihat ada Admin yang mengatur sistem pariwisata Jelitik ini secara online dan melakukan pengelolaan data pariwisata ketika ada acara atau event yang dapat menarit minat orang untuk berkunjung. Masyarakat dapat mengakses sistem pariwisata melalui Internet sehingga bisa mengetahui informasi wisata yang ada di Jelitik, Kabupaten Bangka.

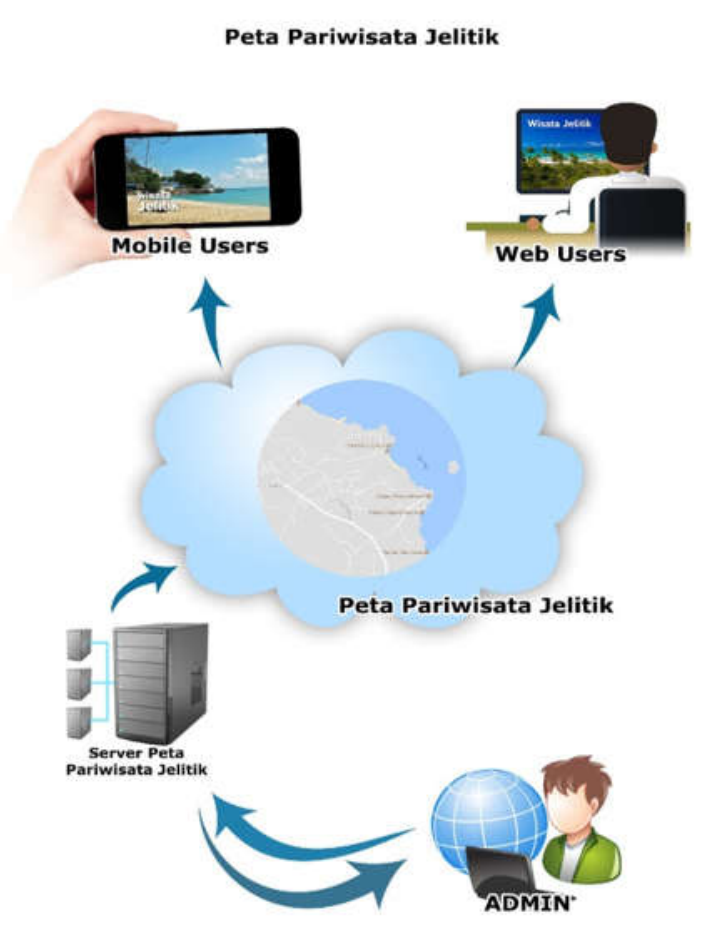

Gambar 1. Arsitektur Peta Wisata Jelitik

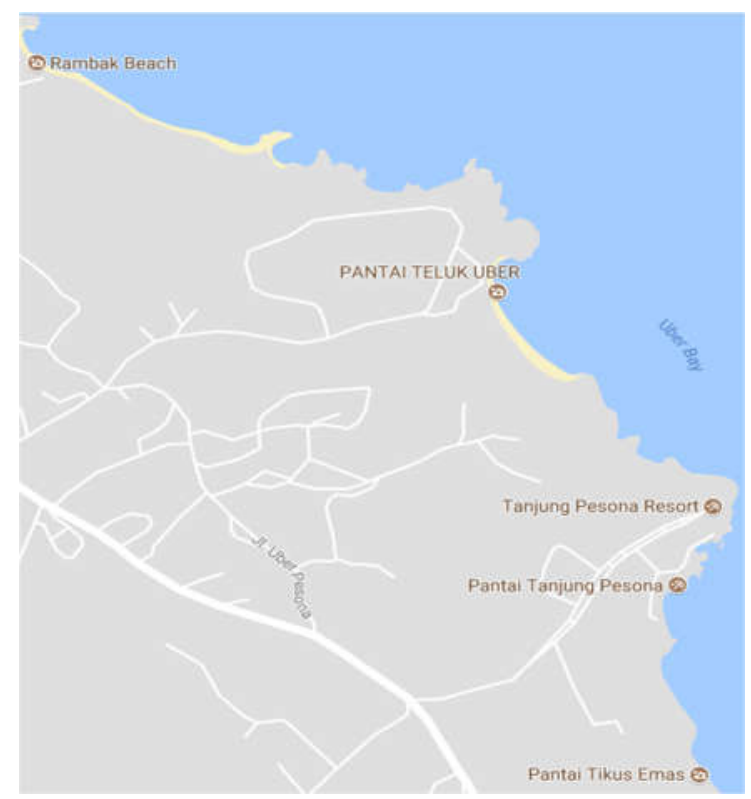

Gambar 2. Peta Objek Wisata Pantai di Jelitik

Peta wisata kawasan Jelitik dapat dilihat pada Gambar 2. Pada Gambar 2, dapat dilihat letak pantai pantai tersebut berdekatan dan masing masing pantai mempunyai kelebihan tersendiri. Guna peta wisata ini memperlihatkan bahwa kawasan Jelitik mempunyai banyak pantai yang 
indah untuk dikunjungi dengan jarak yang tidak terlalu jauh. Jelitik dapat fokus untuk pengembangan wisata pantai mereka untuk menarik wisatawan datang berkunjung.

Pada Gambar 3. dapat dilihat salah satu keindahan Pantai Tanjung Pesona di Jelitik yang sudah terkenal di Bangka dan di luar.

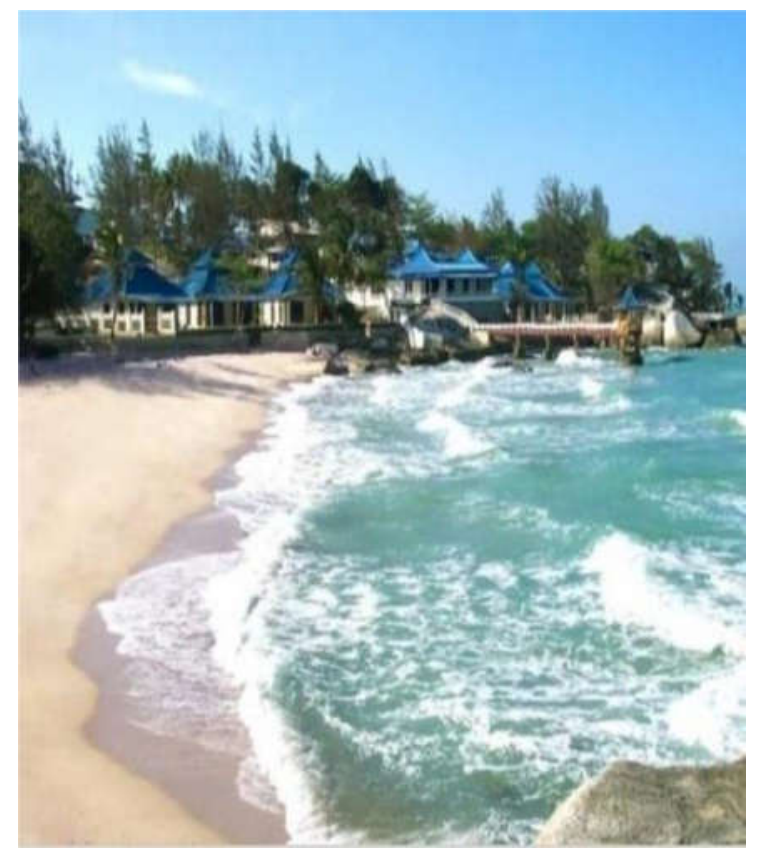

Gambar 3. Pantai Tanjung Pesona

( www.agoda.com)

\section{HASIL DAN PEMBAHASAN}

Peta wisata Jelitik ini akan memberikan gambaran mengenai lokasi wisata yang ada di Jelitik dan bagaimana rute untuk menuju lokasi tersebut baik dari bandara maupun darin pusat kota. Website ini selain berisikan peta wisata juga akan menunjukkan profil wisata dan fasilitas yang ditawarkan oleh tempat wisata yang ada di Jelitik. Dengan adanya website ini diharapkan akan memudahkan orang dalam berkunjung ke Jelitik dan pantai pantai nyang ada di Jelitik. Didalam website memuat spot foto yang menarik dan terdapat informasi mengenai tempat wisata seperti informasi deskripsi pantai, fasilitas tempat wisata, dan lain sebagainya. Pembuatan website pariwisata berfungsi untuk mengenalkan pariwisata yang terdapat di Kelurahan Jelitik agar lebih dikenal oleh wisatawan lokal dan mancanegara. Sehingga wisatawan dapat dengan mudah mengetahui tempat wisata yang menarik untuk dikunjungi.

Pada Gambar 4 dapat dilihat tampilan utama website wisata Jelitik yang menampilkan foto pemandangan yang akan menarik wisatawan untuk berkunjung. Website ini juga berisikan profil tempat wisata yang ada di Jelitik, Bangka sehingga memudahkan pengunjung mengetahui tentang lokasi wisata pantai yang ada di Jelitik.

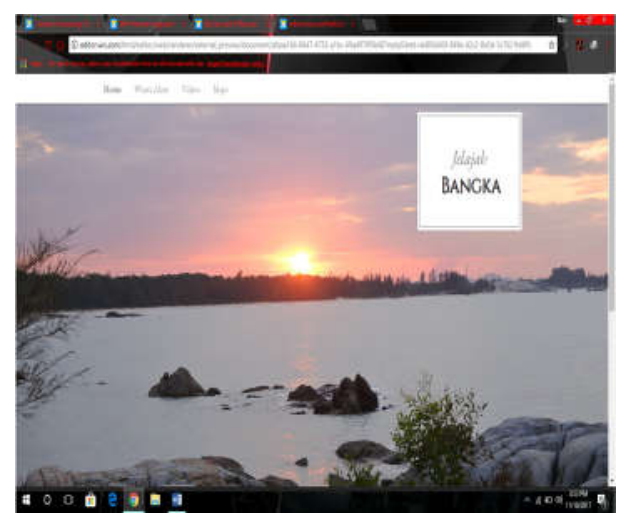

Gambar 4. Tampilan Website Objek Wisata Jelitik

Pada Gambar 5 dapat dilihat tampilan utama foto tentang Pantai tentang indahnya pantai di Jelitik yang dapat menarik wisatawan untuk berkunjung

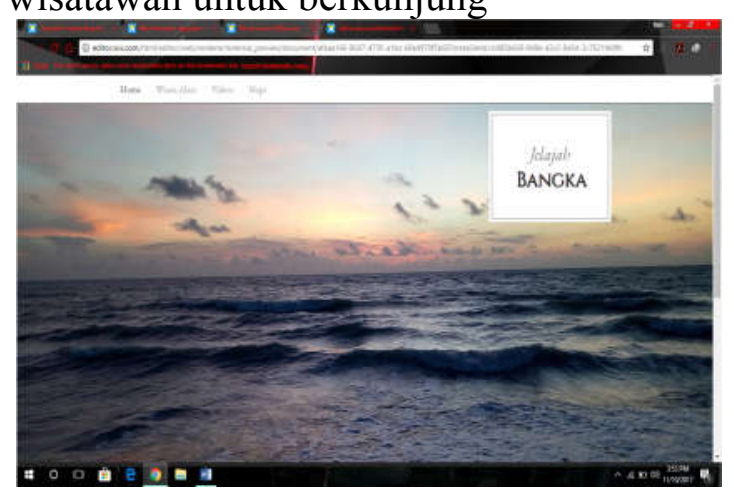

Gambar 5. Tampilan Halaman Depan 


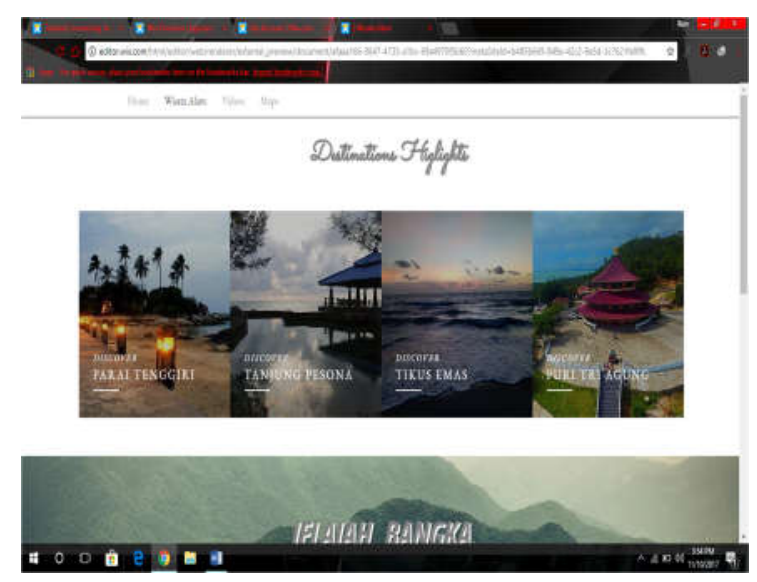

Gambar 6. Laman Deskripsi Lokasi Wisata Di Jelitik

Pada Gambar 6, merupakan halaman untuk informasi profil dari wisata pantai yang ada di Jelitik dengan tambahan Puri Tri Agung sebagai spot tempat wisata yang menarik. Dengan tampilan ini dapat menarik orang untuk berkunjung dan mendapatkan informasi yang lengkap tentang destinasi wisata yang ada di Jelitik.

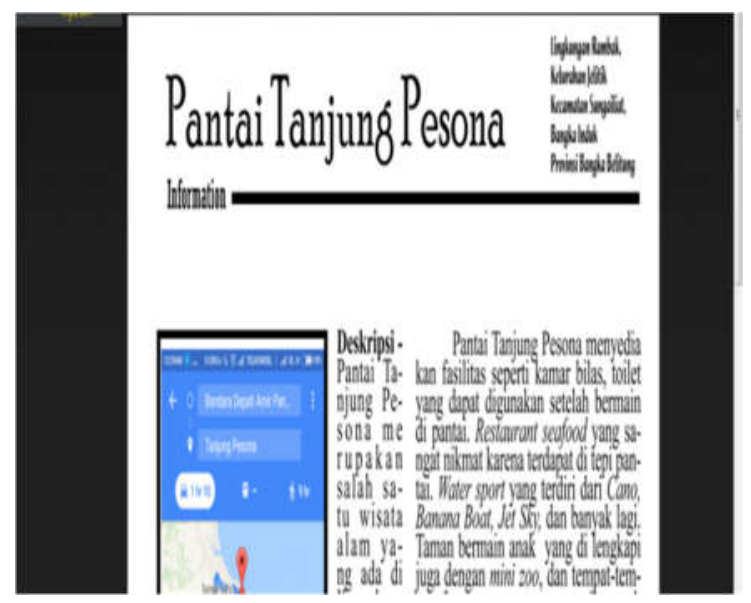

Gambar 7. Contoh Profil Pantai Tanjung

Pesona

Pada Gambar 7. dapat dilihat bagaimana profil wisata pantai tanjung Pesona yang ada di Jelitik, Bangka. Profil ini dibuat dengan tujuan agar wisatawan lebih mengenal tentang Pantai Tanjung Pesona dan orang luar yang belum mengetahui tentang Pantai Tanjung Pesona dapat tertarik untuk datang setelah melihat profil dan foto foto dari Pantai Tanjung Pesona ini.
Pada Gambar 8 merupakan koleksi video dari pemandangan yang ada di pantai pantai yang ada di Jelitik yang memungkinkan orang tertarik untuk berkunjung. Video ini diambil dari youtube dan dibuat link sehingga bisa langsung dibuka di website ini. Dengan adanya fitur video ini diharapkan lebih menarik orang untuk datang. Video juga akan dipilih sehingga video yang benar benar menarik yang akan ditampilkan untuk pengunjung website ini.
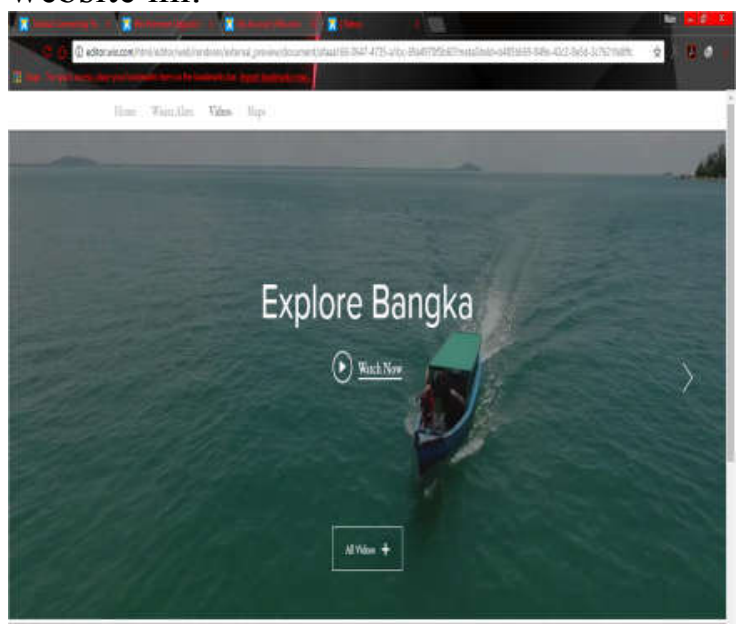

ม 00 ติ

Gambar 8. Tampilan Halaman Fitur Video
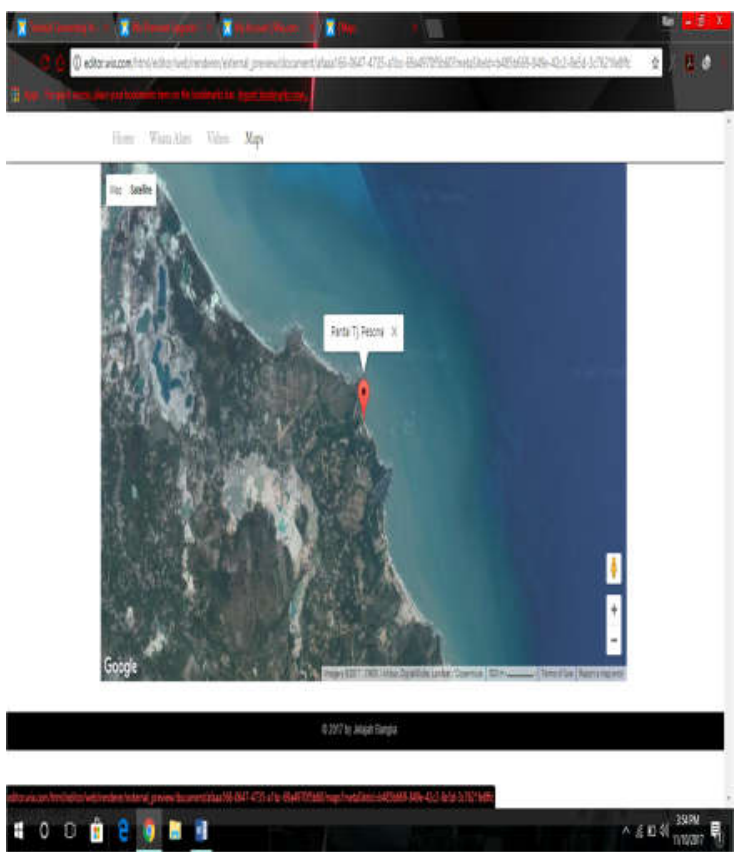

Gambar 10. Tampilan Lokasi Pantai

Tanjung Pesona 
Pada Gambar 10 menunjukkan lokasi Pantai Tanjung Pesona menggunakan satelit serta akan dikembangkan menggunakan Google Maps. Dengan begitu akan memudahkan dalam memberikan peta destinasi wisata yang ada di Jelitik

\section{A. Pengujian dan Analisa yang akan dilakukan}

Dalam tahapan ini dilakukan pengujian terhadap sistem yang telah dibuat dengan cara memeriksa sistem yang dibangun, memeriksa integrasi sistem dengan jaringan Internet dan aplikasi android, dan menguji apakah sistem telah siap digunakan. Untuk pengujian sisetm bimbingan secara keseluruhan akan dilakukan tahapan berikut ini, yaitu:

1. Pengujian data destinasi wisata di Jelitik, Bangka apakah telah sesuai lengkap

2. Pengujian upload data tampilan wisata informasi yang dikirimkan di web database dapat sesuai dengan yang dikirimkan oleh admin.

3. Pengujian web database sudah terkoneksi dengan Internet untuk sistem informasi wisata ini

Pengujian penggunana sistem informasi wisata ini oleh pengguna apakah sistem telah berjalan dengan baik di website

\section{KESIMPULAN}

Sistem informasi objek wisata ini akan dibangun berbasis webserver menggunakan $\mathrm{PhP}$ dan MySQL untuk memudahkan dalam pengelolaan website serta dapat diakses dengan Internet. MySQL digunakan untuk database pantai, hotel dan lain lain. Website ini memberikan informasi tentnag peta destinasi wisata yang ada di Jelitik yaitu Pantai Rambak, Tikus, Tanjung Pesona,
Pesona Bay dan Tikus Mas. Peta ini untuk memudahkan wisatawan dalam berkunjung ke Jelitik dan menikmati keindahan wisata pantai yang ada di Jelitik. Dengan website ini diharapkan pengunjung mendapatkan informasi yang lengkap ketika berkunjung ke Jelitik dan mengetahui tentang destinasi wisata pantai yang ada di Jelitik. Dengan website ini diharapkan dapat meningkatkan kunjungan wisatawan ke Jelitik dan memperkenalkan wisata pantai yang di Jelitik. Website ini juga menginformasikan profil dan fasilitas yang ada di pantaipantai tersebut.

\section{DAFTAR RUJUKAN}

Al Fatta. Hamid, "Analisis dan Perancangan Sistem Informasi", Yogyakarta: Andi, 2007.

Allen, G. 2012. Beginning Android 4. Penerbit Apress. New York.

Hakim, L. 2013.Proyek Website Super Wow! PHP \& JQuery. Penerbit Lokomedia. Yogyakarta.

Kadir, A., 2006. Pengenalan Sistem Informasi.

Yogyakarta: Andi Offset.

Utami. E.. \& Hartanto. A. D.. 2012. Sistem Basis Data menggunakan Microsoft SOL Server 2005. Yogyakarta: Penerbit Andi.

PENGERTIAN PARIWISATA

MENURUT AHLI DAN UNDANGUNDANG KEPARIWISATAAN (http://ekonomisosiologigeografi.blogspot. co.id/2015/10/ pengertian-pariwisatamenurut-ahli dan.html)

PENGERTIAN

PARIWISATA

(http://assharrefdino.blogspot.co.id/2013/1

1/pengertian-pariwisata.html)

Tourism

(https://en.m.wikipedia.org/wiki/Tourism)

Pariwisata

(https://id.wikipedia.org/wiki/Pariwisata 